\title{
Predictors of delirium in older patients at the emergency department: a prospective multicentre derivation study
}

\author{
Emmanuelle Béland ${ }^{1} \cdot$ Alexandra Nadeau ${ }^{2} \cdot$ Pierre-Hugues Carmichael $^{3} \cdot$ Valérie Boucher $^{2} \cdot$ Philippe Voyer $^{1,2}$. \\ Mathieu Pelletier ${ }^{1,4} \cdot$ Émilie Gouin $^{5} \cdot$ Raoul Daoust $^{6,7} \cdot$ Simon Berthelot ${ }^{1,2} \cdot$ Marie-Eve Lamontagne $^{1,8}$. \\ Michèle Morin $^{1,2} \cdot$ Stéphane Lemire ${ }^{1,2} \cdot$ Thien Tuong Minh Vu ${ }^{7,9} \cdot$ Marcel Émond $^{1,2}$
}

Received: 12 June 2020 / Accepted: 14 August 2020 / Published online: 4 January 2021

(c) Canadian Association of Emergency Physicians (CAEP)/ Association Canadienne de Médecine d'Urgence (ACMU) 2021

\begin{abstract}
Objective The objective of this study was to identify the predictors of incident delirium in this high-risk population.

Methods This study was a planned sub-analysis of the INDEED multicentre cohort study. We recruited patients aged $\geq 65$, independent/semi-independent, with an emergency department (ED) length of stay $\geq 8 \mathrm{~h}$ and admitted to any hospital ward. Patients were followed up during their ED stay up to $24 \mathrm{~h}$ after ward admission. Sociodemographic characteristics, comorbidities, functional status (OARS), illness severity, level of frailty, cognitive status (TICS-m) and ED/patient environment evaluation were collected during initial interview. Patients were screened for delirium twice a day using the Confusion Assessment Method. Multivariate logistic regression was performed to identify the predictors of delirium.

Results Incident delirium was detected in 68 patients of the 612 patients included (11\%). Initially, seven candidate predictors were included in a regression model, of which four were retained using a stepwise selection procedure. Presence of cognitive impairment at baseline (OR 3.6, $p<0.001$ ), absence of mobilization during the whole ED length of stay (OR 3.3, $p=0.002$ ), longer ED length of stay (OR 1.02, $p=0.006$ ) were associated with a higher risk of incident delirium while higher functional status was associated with a lower risk (OR $0.8, p<0.001)$.

Conclusion More work is needed to determine which tool(s) are most appropriate for the ED use to increase delirium screening compliance among health professionals working in this department. It is really the first step to be able to suggest interventions to decrease delirium incidence.
\end{abstract}

Keywords Delirium $\cdot$ Predictor factors $\cdot$ Emergency department

Marcel Émond

marcelemond1@me.com

Université Laval, Québec, Canada

2 Centre de Recherche du CHU de Québec-Université Laval, Hôpital de L’Enfant-Jésus, Québec, Canada

3 Centre D'excellence Sur Le Vieillissement de Québec, Québec, Canada

4 Centre Intégré de Santé Et de Services Sociaux de Lanaudière, Joliette, Canada
5 Centre Hospitalier Régional de Trois-Rivières, Trois-Rivières, Canada

6 Centre de Recherche de L'Hôpital du Sacré-Cœur de Montréal, Montréal, Canada

7 Université de Montréal, Montréal, Canada

8 Centre Interdisciplinaire de Recherche en Réadaptation Et Intégration Sociale, Québec, Canada

$9 \quad$ Centre de Recherche du Centre Hospitalier de L'Université de Montréal, Montréal, Canada 


\section{Résumé}

Objectif L'objectif de cette étude était d'identifier les prédicteurs du délirium incident dans cette population à hautrisque. Méthodes Cette étude était une sous-analyse planifiée de l'étude de cohorte multicentrique INDEED. Nous avons recruté des patients âgés de $\geq 65$ ans, indépendants/semi-indépendants, ayant une durée de séjour au département d'urgence (DU) $\geq$ $8 \mathrm{~h}$ et admis dans n'importe quel service. Les patients ont été suivis pendant leur séjour aux urgences jusqu'à $24 \mathrm{~h}$ après leur admission. Les caractéristiques sociodémographiques, les comorbidités, l'état fonctionnel (OARS), la gravité de la maladie, le niveau de fragilité, l'état cognitif (TICS-m) et l'évaluation de l'environnement des urgences/patients ont été recueillis lors de l'entretien initial. Les patients ont été soumis à un dépistage du délirium deux fois par jour à l'aide de la méthode d'évaluation de la confusion. Une régression logistique multivariée a été effectuée pour identifier les prédicteurs de délirium. Résultats Le délirium incident a été détecté chez 68 des 612 patients inclus (11\%). Au départ, sept prédicteurs candidats ont été inclus dans un modèle de régression, dont quatre ont été retenus par une procédure de sélection par étapes. La présence d'un déficit cognitif initial (RC 3,6, $p<0,001)$, l'absence de mobilisation pendant toute la durée du séjour à l'urgence (RC $3,3, p=0,002)$, une durée de séjour plus longue à l'urgence ( $\mathrm{RC} 1,02, p=0,006)$ étaient associées à un risque plus élevé de délirium incident, tandis qu'un état fonctionnel plus élevé était associé à un risque plus faible ( $\mathrm{RC} 0,8, p<0,001)$.

Conclusions Des travaux supplémentaires sont nécessaires pour déterminer quel(s) outil(s) sont les plus appropriés au DU afin d'accroître le dépistage du délirium par les professionnels de santé travaillant dans ce service. C'est vraiment la première étape pour pouvoir proposer des interventions visant à diminuer l'incidence du délirium.

\section{Clinician's capsule}

\section{What is known about the topic?}

Literature is scarce regarding the predisposing factors of delirium in the emergency department.

\section{What did this study ask?}

The aim of this study was to confirm predicting factors of developing delirium in older emergency department patients.

\section{What did this study find?}

Cognitive impairment, lower baseline functional status, not being mobilized over a long period and prolonged emergency department stay are risk factors.

\section{Why does this study matter to clinicians?}

Early identification of patients at risk could decrease the incidence of delirium by quickly acting on modifiable risk factors.

\section{Introduction}

Population ageing will greatly impact our health care system as the proportion of seniors is expected to increase rapidly until 2031, when all the baby boomers will have reached 65. Seniors could represent between 23 and $25 \%$ of the total population in 2036 [1]. Because having access to their family physician may be difficult [2], Canadian seniors are frequently left with no other option than to go to the emergency department (ED) to get the medical attention they need. However, a simple visit to the ED can render them vulnerable [3] and trigger major complications. One of those common complications is delirium, a serious neuropsychiatric condition of acute onset with a fluctuating course of disturbance in consciousness, attention, orientation, memory, thought, perception and behavior [4]. Delirium is known to have significant consequences on affected patients. Possible adverse outcomes include cognitive decline, increased hospital length of stay [5], unplanned return to ED or hospital admission [6], and nursing home placement [6]. Consequences of delirium may also have long-term effect on patients, as affecting functional recovery [6], cognition [7], and increased risk of mortality [8]. Current recommendations state that all older ED patients with risk factors for developing delirium should be screened daily [9]. However, despite those recommendations and the existence of screening tools, recent studies have determined that over $65 \%$ of delirium cases are not identified in this setting [10, 11].

Several predisposing factors of delirium have been proposed in different types of inpatients. However, the context of emergency department could be contrasting to ward, with its overcrowding, fast-paced and stress due to acute unknown health problem. Despite those differences, literature is scarce regarding the predisposing factors of delirium in the $\mathrm{ED}$ $[12,13]$. An ED stay of over $12 \mathrm{~h}$ has been identified as the strongest independent predictor of developing delirium in older patients $[12,14]$. Other predisposing factors refer to a patient's vulnerability and include older age, pre-existing cognitive impairment, loss of independence, loss of sensorium, polypharmacy and associated medical comorbidities [15]. Nevertheless, preventive recommendations from the National Institute for Health and Clinical Excellence (NICE) focus on modifiable factors, such as disorientation, dehydration, malnutrition, hypoxia, decreased mobility, pain and sleep hygiene [16].

In 2011, the Quebec Health Ministry has delivered a frame of reference, the senior-friendly approach, to sensitize and equip hospital centres and health care providers to 
make these environments more senior-friendly [16]. This frame of reference contained recommendations for improvements to be made in hospital centres and clinical procedures when meeting an elder. The main goal of the senior-friendly approach was to prevent deleterious effects of a single visit for an acute health problem, such as delirium.

The aim of this study was to confirm predicting factors of developing delirium in older emergency department patients. This is the first Quebec multicentre study to investigate the predisposing factors of developing delirium in older ED patients, especially after the implementation of the Health Ministry initiative.

\section{Methods}

\section{Study design and setting}

This project is part of the Incidence and Impact Measurement of ED-induced Delirium study (INDEED) [17]. This prospective multicentre cohort study included patients recruited within five EDs (two university-affiliated level 1 trauma centres, one university-affiliated hospital, and two regional hospitals) across the province of Quebec. Patients were recruited in two phases (between March and July 2015, and between February and May 2016).

\section{Population}

Patients were included if they 1) were aged 65 and over, 2) had an ED stay of at least $8 \mathrm{~h}, 3$ ) were admitted to any hospital ward, 4) were independent or semi-independent (able to perform five of seven activities of daily living). Patients were excluded if they 1) had unstable medical condition requiring intensive care, 2) delirium was already present upon consultation to the ED (prevalent delirium) or within $8 \mathrm{~h}$ of arrival, 3) were unable to communicate and consent in either French or English, 4) were residents of a long-term care facilities or 5) had a history of a psychiatric disorders (such as schizophrenia, psychotic symptoms and bipolar disorder). Current Canadian ED recommendations state that length of stay in older patients should be kept under $8 \mathrm{~h}$; therefore, we chose this cut-off point as opposed to the 10 - or 12 -h exposure previously determined to be a predictor of delirium [12, 14].

\section{Data collection and processing}

After identifying potential study participants using the ED patient tracking software (Sunday to Saturday, between 8 am and $8 \mathrm{pm}$ ), research assistants met potential participant at least $8 \mathrm{~h}$ after ED arrival to obtain informed consent and to proceed to the first interview. Participants were assessed twice a day (with at least $6 \mathrm{~h}$ between assessments) during their stay in ED and for up to $24 \mathrm{~h}$ after admission to the hospital ward. Each site's team of research assistants received standardized training by an experienced member of the mentoring team of the Centre d'Excellence sur le Vieillissement de Québec, who also specializes in the administration of the CAM. They also attended a group training session conducted by the study coordinator and an experienced research nurse and underwent a 5-h personalised field training. They were also provided with a detailed training manual. In addition, ongoing support and supervision by the study coordinator was made to ensure inter-rater reliability. This research project was approved by the CHU de Québec-Université Laval Research Ethics Board.

\section{Outcome measures collected only once}

Sociodemographic characteristics, comorbidities (Charlson Comorbidity Index) [18], functional status (Older Americans Resources and Services scale [OARS]) [19], illness severity (Acute Physiological and Chronic Health Evaluation II [APACHE II]) [20] and level of frailty (Clinical Frailty Scale) [21] were obtained during initial interview. Patients' cognitive status was evaluated in person using the Telephone Interview for Cognitive Status-modified (TICSm) [22], as the protocol included 60 days of telephonic follow-up evaluating, among others, cognitive status. A TICS-m score $\leq 27$ indicates cognitive impairment [23]. ED and patient environment evaluation were also assessed during initial evaluation, and included information, such as presence of proper lighting, patient's hydration (presence of saliva under the tongue/glass of water, absence of fasting), presence of physical restraints or medical procedures limiting movement (bladder catheter, intravenous line, solute, oxygen), access to a watch with the right information for spatio-temporal orientation, and the wearing of sensory aids when necessary. Patients' ED length of stay was measured from the time of triage up to patient transfer to the hospital ward. Hospital length of stay was calculated from the time of ED triage up to hospital discharge. The proportion of time spent in the corridor between the initial interview and admission to the hospital ward was also calculated.

\section{Outcome measures collected repeatedly}

The Confusion Assessment Method (CAM) [24] was our primary outcome and used during the first interview and then twice daily to detect incident delirium. This test was administered by trained research assistants; however, it has been shown that sensitivity and specificity could be similar to administration of the test by geriatrician [25]. A patient with a positive CAM during the initial interview resulted in the exclusion of that patient. A CAM test is positive 
Table 1 Characteristics of included patients, according to their delirious status

\begin{tabular}{lllr}
\hline & Delirium & Non delirium & $p$ value \\
& $N=68$ & $N=544$ & \\
\hline Patients' characteristics & & & \\
Age, mean (SD) & $80.6(8.8)$ & $76.4(7.6)$ & $<\mathbf{0 . 0 0 1}$ \\
Female, $n$ (\%) & $36(52.9)$ & $275(50.6)$ & 0.71 \\
Delirium Index score, mean (SD) & $4.9(2.9)$ & $1.1(1.5)$ & $<\mathbf{0 . 0 0 1}$ \\
OARS score, mean (SD) & $24.2 \pm 2.7$ & $25.9 \pm 2.4$ & $<\mathbf{0 . 0 0 1}$ \\
TICS-m score, mean (SD) & $27.7 \pm 6.5$ & $31.6 \pm 5.3$ & $<\mathbf{0 . 0 0 1}$ \\
Charlson score, mean (SD) & $2.3 \pm 2.5$ & $2.0 \pm 1.9$ & 0.28 \\
APACHE II score, mean (SD) & $10.8(5.7)$ & $11.5(5.9)$ & 0.39 \\
Clinical Frailty Scale score, mean (SD) & $4.1(1.2)$ & $3.4(1.2)$ & $<\mathbf{0 . 0 0 1}$ \\
ED LOS, mean hours (SD) & $43.3(23.8)$ & $36.6(20.4)$ & 0.01 \\
Hospital LOS, mean hours (SD) & $314.8(233.0)$ & $207.6(200.5)$ & $<\mathbf{0 . 0 0 1}$ \\
Environmental factors & & & \\
Proportion of ED LOS spent in the corridor, $\%$ & $4.5(1.5)$ & $9.7(2.6)$ & $\mathbf{0 . 0 2}$ \\
Sufficient lighting at IE, $n$ (\%) & $38(56.7)$ & $297(54.9)$ & 0.78 \\
Sufficient hydration at IE, $n$ (\%) & $27(40.3)$ & $187(35.0)$ & 0.39 \\
Physical constraints at IE, $n$ (\%) & $33(50.0)$ & $267(49.5)$ & 0.94 \\
Medical equipment limiting movement at IE, $n(\%)$ & $43(71.7)$ & $355(70.2)$ & 0.83 \\
Good spatio-temporal orientation at IE, $n(\%)$ & $31(45.6)$ & $291(53.6)$ & 0.21 \\
Participants needing visual or hearing aids IE, $n(\%)$ & $64(94.1)$ & $506(93.0)$ & 0.73 \\
Use of visual or hearing aids during IE, $n(\%)$ & $51(75.0)$ & $403(74.1)$ & 0.87 \\
Controlled pain during ED LOS, $n$ (\%) & $10(17.5)$ & $85(18.6)$ & 0.85 \\
$\geq 1$ mobilization during ED LOS, $n(\%)$ & $40(71.4)$ & $450(90.2)$ & $<\mathbf{0 . 0 0 1}$ \\
\hline
\end{tabular}

Bold: $p$ value $<0.05$. ED Emergency department; $L O S$ length of stay; $I E$ initial evaluation according to the sensitive method if the following is present: 1) acute onset or fluctuation, and 2) inattention, plus either 3 ) disorganized thinking or 4) altered level of consciousness [26]. The Delirium Index [27] was also administered to measure the severity of delirium symptoms, graded from 0 to a maximum score of 21 and where a higher score indicates more serious symptoms. During initial interview and followups, a visual analogue scale was used to evaluate patient pain levels, on a scale of $0-100$, where 100 indicates the worst pain possible. As it has been suggested in the literature [28], we considered that pain was controlled with a reduction of 13 points in comparison to baseline. Research assistants also verified whether the patient was mobilized between each follow-up by asking this information directly to the patient and to the attending nurse and by reviewing the medical and nurses' notes.

\section{Data analysis}

Patients with and without delirium were compared using Student's $t$ test or chi-square test when appropriate. The level of statistical significance for those tests was set at $p<0.05$. For the predictive model, we considered predictors of delirium suggested in the literature. However, to respect a ratio of one variable to ten events of delirium [29], we included the most significant variables from this initial analysis. A stepwise selection method was applied to the candidate predictors with entry at the $10 \%$ level and exclusion at the $5 \%$ level to build a parsimonious model. Analyses were performed using Statistical Analysis System (SAS Institute Inc., Cary, NC, USA).

\section{Results}

A total of 612 patients were included. The overall cumulative incidence of ED-induced delirium in our cohort was $11 \%$. The characteristics of delirious and non-delirious patients are presented in Table 1. Our delirious group was older, had lower functional status, had a higher level of frailty and was more cognitively impaired at baseline than the non-delirious group $(p<0.001)$. Considering our cut-off for cognitive status, $45 \%$ of participants who developed a delirium presented cognitive impairment compared to $17 \%$ of those who did not. A larger proportion of the delirious group was also considered as frail (68\% vs $50 \%)$.

A total of seven candidate predictors were considered for inclusion in the logistic regression model: age, the OARS 
Fig. 1 Estimated Odds Ratios with $95 \%$ wald confidence limits from logistic stepwise regression model for prediction of delirium. $E D$ emergency department, LOS length of stay

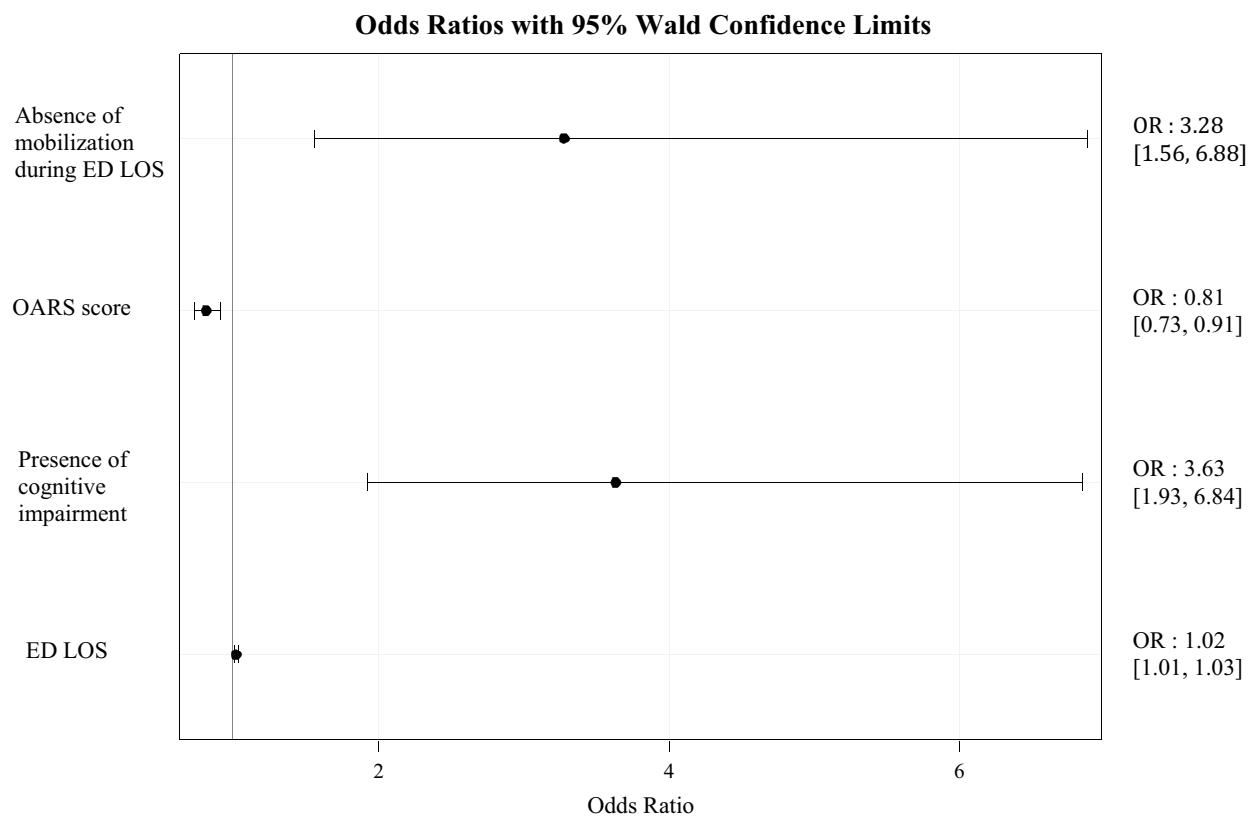

score, the presence of frailty, the presence of cognitive impairment, ED length of stay, proportion of time spent in the ED corridor, and the absence of mobilization during the whole ED length of stay. The complete initial model gave similar fit to the data as the final parsimonious model (AIC of 301.23 and 301.93, respectively) as well as similar predictive accuracy (ROC AUC of 0.82 and 0.81 , respectively). According to our model, predictors of incident delirium up to $24 \mathrm{~h}$ after ward admission are cognitive impairment (OR 3.6, $p<0.001)$, absence of mobilization during the whole ED stay (OR 3.3, $p=0.002$ ), longer ED length of stay (OR $1.02, p=0.006$ ), while a higher OARS score, indicating higher functional status, is protective (OR $0.8, p<0.001$ ) (Fig. 1).

\section{Discussion}

\section{Interpretation of findings}

This is the first Quebec multicentre study to investigate the predisposing factors of developing delirium in older ED patients. In our cohort, absence of mobilization during ED stay, presence of cognitive impairment and ED length of stay were statistically significant predicting factors of developing delirium, while greater functional status was a protective factor.

\section{Comparison to previous studies}

The literature on predictors of incident delirium after presenting to the ED setting is scarce $[12,13]$. Still, our results confirm those reported in previous studies where cognitive impairment and dementia are important predisposing factors to develop a delirium during an ED visit $[12,13]$. Similarly, ED length of stay being associated with higher risk of developing delirium is consistent with results of Bo et al. [12]. However, all previous studies obtained older age as a predisposing factor for delirium [12, 13, 30], contrary to our results, despite similar age inclusion criteria and mean age of included participants [13]. If considering other settings, modifiable and non-modifiable factors suggested to predict the development of incident delirium in hospitalized patients include older age and pre-existing cognitive impairment, but also parameters, such as functional and sensory impairments, and comorbidities [30]. However, whether in EDs or on a hospital ward, the broad variable definitions, the various patient outcomes used, and the non-systematic assessment of delirium (which was only be performed once daily on week days in some studies) may explain the variability observed in the predicting factors obtained and limit reproduceable results.

\section{Clinical implications}

Our study is the first to evaluate predicting factors of incident delirium in the ED following the wide implementation of the Quebec Health Ministry senior-friendly approach [16]. The adapted approach includes systematic preventive interventions aimed at maintaining functional status (i.e. mobilization, pain control, physical constraints, medical equipment limiting movement), skin integrity, nutritional health (i.e. hydration), elimination, cognitive and affective state (i.e. proper lighting, spatial-temporal orientation, visual and 
hearing aids, limiting relocation) and sleep. However, the homogeneity of this approach's implementation throughout the province is still unknown. Our sample had a mean ED length of stay of 43.3 and $36.6 \mathrm{~h}$ for patients who developed delirium and those who did not, respectively. Although ED length of stay appeared to have decreased in the past years in Quebec (90\% percentile at $27.2 \mathrm{~h}$ for people over 65) [31], it still represents ED length of stay superior to the recommendations. Moreover, our results demonstrated that patient mobilization during their ED stay could be a parameter that might be worth investing resources into, considering that none of the five participating sites has a person assigned to the ED to mobilize this clientele. Recruiting adequately trained volunteers dedicated to mobilizing seniors who consult to ED could be a beneficial low-cost solution to our health care system.

\section{Strengths and limitations}

This study presents several strengths. As delirium is a multifactorial syndrome with a fluctuating course [30], the fact that patients were screened for delirium twice a day allowed a more accurate monitoring of the incidence of this condition. We used validated tools, such as the CAM and TICS-m. In addition, our multicentre design allowed a better representation of the older patients usually seen in the ED. Some of our inclusion criteria may have had the effect of excluding patients at higher risk of developing delirium could also be considered a limitation. However, the main objective of the INDEED study was first to investigate prevalence of delirium among more robust older patients.

\section{Conclusion}

Considering the limited ability to suspect and detect delirium among clinicians in the ED [4, 5], early identification of patients at greater risk is recommended to decrease its incidence by quickly acting on modifiable risk factors. Based on our results, patients with cognitive impairment who have a prolonged length of stay in the ED and are not mobilized are at particularly high risk of incident delirium. Therefore, we propose that an increase in resources to mobilize these patients could have a beneficial impact on the incidence of delirium in the ED. More work is needed to determine which tool(s) are most appropriate for the ED use to increase delirium screening compliance among health professionals working in this department. It is really the first step to be able to suggest interventions to decrease delirium incidence.

Acknowledgements The authors would like to thank Suzy Lavoie and research assistants who participated in the recruitment of patients for this study.
Author contributions MÉ had full access to all of the data in the study and takes responsibility for the integrity of the data and the accuracy of the data analysis. He was responsible for design, funding and conduct of the study. VB managed the study. EB, AN and PHC led the statistical analyses and data interpretations. EB and AN wrote the manuscript. MP, RD, ÉG, SB and MÉ were responsible for recruitment at all five sites. PV, MM, SL, MEL and LM are all collaborators of INDEED project. MÉ, VB, PHC, PV, MP, ÉG, RD, SB, MÈL, MM, and SL reviewed and approved the manuscript. Sponsor's role. N/A.

Funding This study was funded by the Fonds Québécois de Recherche en Santé (FQRS 29307).

\section{Compliance with ethical standards}

Conflict of interest The authors have no conflicts.

\section{References}

1. Statistics Canada. Seniors. 2018. Available from: https://www15 0.statcan.gc.ca/n1/pub/11-402-x/2011000/chap/seniors-aines/ seniors-aines-eng.htm. Accessed 10 Aug 2020.

2. Shah TI, Milosavljevic S, Bath B. Determining geographic accessibility of family physician and nurse practitioner services in relation to the distribution of seniors within two Canadian Prairie Provinces. Soc Sci Med. 2017;194:96-104.

3. Bonin-Guillaume S, Durand AC, Yahi Curiel F, Berruyer M, Lacroix O, Cretel-Durand E, et al. Predictive factors for ealy unplanned rehospitalization of older adults after an ED visit: role of the caregiver burden. Aging Clin Exp Res. 2015;27(6):883-91.

4. Cole MG. Delirium in elderly patients. Am J Geriatr Psychiatry. 2004;12(1):7-21.

5. Emond M, Grenier D, Morin J, Eagles D, Boucher V, Le Sage $\mathrm{N}$, et al. Emergency department stay associated delirium in older patients. Can Geriatr J. 2017;20(1):10-4.

6. Miu DKY, Chan CW, Kok C. Delirium amond elderly patients admitted to a post-acute care facility and 3-months outcome. Geriatr Gerontol Int. 2016;16(5):586-92.

7. Krogseth M, Wyller TB, Engedal K, Juliebo V. Delirium is an important predictor of incident dementia among elderly hip fracture patients. Dement Geriatr Cogn Disord. 2011;31(1):63-70.

8. McCusker J, Cole M, Abrahamowicz M, Primeau F, Belzile E. Delirium predicts 12-month mortality. Arch Intern Med. 2002;162(4):457-63.

9. National Institute for Health and Care Excellence. Delirium: prevention, diagnosis and management. 2019. Available from: https ://www.nice.org.uk/guidance/cg103. Accessed 10 Aug 2020.

10. Boucher V, Lamontagne M-E, Nadeau A, Carmichael P-H, Yadav $\mathrm{K}$, Voyer $\mathrm{P}$, et al. Unrecognized incident delirium in older emergency department patients. J Emerg Med. 2019;57(4):535-42.

11. Sugalski G, Ullo M. Making sense of delirium in the emergency department. Emergency Medicine Reports. 2019. Available at https://www.reliasmedia.com/articles/143932-making-sense -of-delirium-in-the-emergency-department. Accessed 5 Apr 2020.

12. Bo M, Bonetto M, Bottignole G, Porrino P, Coppo E, Tibaldi $M$, et al. Length of stay in the emergency department and occurrence of delirium in older medical patients. J Am Geriatr Soc. 2016;64(5):1114-9.

13. Kennedy M, Enander RA, Tardiri SP, Wolfe RE, Shapiro NI, Marcantonio ER. Delirium risk prediction, healthcare use and mortality of elderly adults in the emergency department. JAGS. 2014;62:462-9. 
14. Inouye SK, Charpentier PA. Precipating factors for delirium in hospitalized elderly persons. JAMA. 1996;275(11):852-7.

15. Laurila JV, Laakkonen ML, Timo SE, Reijo TS. Predisposing and precipating factors for delirium in a frail geriatric population. $\mathrm{J}$ Psychosom Res. 2008;65(3):249-54.

16. Ministère de la Santé et des Services Sociaux. Approche adaptée à la personne âgée en milieu hospitalier-Cadre de référence. 2011. Available at http://www.msss.gouv.qc.ca. Accessed 6 Feb 2020.

17. Émond M, Boucher V, Carmichael PH, Voyer P, Pelletier M, Gouin E, et al. Incidence of delirium in the Canadian emergency department and its consequences on hospital length of stay: a prospective observational multicentre cohort study. BMJ open. 2018;8(3):1-9.

18. Frenkel WJ, Jongerius EJ, Mandjes-van Uitert MJ, van Munster BC, de Rooij SE. Validation of the Charlson Comorbidity Index in acutely hospitalized elderly adults: a prospective cohort study. J Am Geriatr Soc. 2014;62(2):342-6.

19. Fillenbaum GG, Duke U. Multidimensional functional assessment of older adults: the Duke Older Americans Resources and Services procedures. Hillsdale, NJ: L Erlbaum Associates; 1988. p. 179.

20. Knaus WA, Draper EA, Wagner DP, Zimmerman JE. APACHE II: a severity of disease classification system. Crit Care Med. 1985;13(10):818-29.

21. Rockwood K, Song X, MacKnight C, Bergman H, Hogan DB, McDowell I, et al. A global clinical measure of fitness and frailty in elderly people. CMAJ. 2005;173(5):489-95.

22. de Jager C, Budge M, Clarke R. Utility of TICS-m for the assessment of cognitive function in older adults. Int J Geriatr psychiatry. 2003;18(4):318-24.

23. Knopman DS, Roberts RO, Geda YE, Pankratz VS, Christianson $\mathrm{TJH}$, Petersen RC, et al. Validation of the telephone interview for cognitive status-modified in subjects with normal cognition, mild cognitive impairment, or dementia. Neuroepidemiology. 2010;34(1):34-42.

24. Inouye SK, van Dyck CH, Alessi CA, Balkin S, Siegal AP, Horwitz RI. Clarifying confusion: the confusion assessment method. A new method for detection of delirium. Ann Intern Med. 1990;113(12):941-8.

25. Monette J, Galbaud du Fort G, Fung SH, Massoud F, Moride Y, Arsenault L, et al. Evaluation of the Confusion Assessment Method (CAM) as a screening tool for delirium in the emergency room. Gen Hosp Psychiatry. 2001;23(1):20-5.

26. Inouye SK. The Confusion Assessment Method (CAM): training manual and coding guide Boston: Hospital Elder Life Program. 2003. Available from: www.hospitalelderlifeprogram.org. Accessed 3 Aug 2020.

27. McCusker J, Cole MG, Dendukuri N, Belzile E. The delirium index, a measure of the severity of delirium: new findings on reliability, validity, and responsiveness. J Am Geriatr Soc. 2004;52(10):1744-9.

28. Kelly AM. The minimum clinically significant difference in visual analogue scale pain score does not differ with severity of pain. Emerg Med J. 2001;18:205-7.

29. Hosmer DWJ, Lemeshow S, Sturdivant RX. Applied logistic regression. 3rd Edition ed. Statistics WSiPa; 2013. p. 528.

30. Lindroth H, Bratzke L, Purvis S, Brown RM, Coburn M, MrKobrada $\mathrm{M}$, et al. Systematic review of prediction models for delirium in the older adult inpatient. BMJ open. 2018;8(4):1-22.

31. Institut Canadien d'Information sur la Santé. Nombre de visites au service d'urgence et durée du séjour, 2018-2019. 2018. Available from: https://www.cihi.ca/fr/search?query-all=temps+d\%27att ente $+\% \mathrm{C} 3 \% \mathrm{~A} 0+1 \% 27$ urgence $\&$ Search + Submit $=$. Accessed 21 Apr 2020. 